Dermatology 2011;223:216-218

DOI: $10.1159 / 000327678$

\section{Erythema Scarlatiniforme Desquamativum Recidivans (Féréol-Besnier) - Report of Three Cases Localized to the Thumb}

\section{G. Marazza ${ }^{\mathrm{a}}$, H. Beltraminellib , C. Mainetti ${ }^{\mathrm{a}}$}

a Servizio di Dermatologia, Ospedale Regionale Bellinzona e Valli, Bellinzona, and ${ }^{b}$ Dermatologische Klinik, Inselspital Bern, Bern, Switzerland

\section{Key Words}

Féréol-Besnier erythema $\cdot$ Erythema scarlatiniforme desquamativum recidivans $\cdot$ Acral scaling $\cdot$ Scarlatiniform scaled erythema

\section{Introduction}

Erythema scarlatiniforme desquamativum recidivans (ESDR) of Féréol-Besnier is a rare but well-described skin disease, characterized by an erythematous rash followed by an extensive desquamation of the involved skin [1]. Generalized or localized - to hands and feet - forms are described in the literature. The former are generally associated with a more pronounced prodromal phase, in which patients could develop general malaise, headache, muscle and joint pain or gastro-intestinal symptoms [2]. The course of the disease is typically characterized by self-remitting episodes during 2-4 weeks, with relapses that could be observed after a variable time (days to years), in general shorter and milder than the first. We read with interest the papers of Braun-Falco et al. [3] and Beltraminelli and Itin [4], and we report in this letter 3 cases of ESDR localized to the thumb (table 1). This is to our knowledge the first series of cases localized to a single finger.

\section{Case Reports}

Patient 1. A 22-year-old woman, without notable medical history, without current medication, had complained for 1 year of recurrent episodes of erythema, followed by swelling, itching and desquamation to the distal portion of the right thumb (fig. 1a-c). The disease lasts about 2 weeks, it is self-remitting, and relapses are observed every month. The patient does not describe any trigger factor, in particular neither infections nor drugs, and does not present any prodromal phase. Blood analysis including white blood cell count, liver and renal function were normal, except a slight elevation of the blood sedimentation rate $(38 \mathrm{~mm} / \mathrm{h})$. Bacterial culture of the pharyngeal cavity revealed a normal flora.

Patient 2. A 66-year-old man was referred in April 2001 to our consultation due to recurrent episodes of erythema, swelling and lamellar peeling of his left thumb for 3 years (fig. 2). He had recently been operated for a tubulovillous adenoma of the ileocaecal valve. These manifestations were just preceded by a slight general malaise, and no clear trigger factor was identified. The patient has presented about 5 episodes per year, and the evolution was spontaneously favourable in each case. Topical treatment with topical corticosteroids, vitamin D derivates or salicylic acid creams did not change the course of the disease. All the laboratory findings (blood count, blood sedimentation rate, liver thyroid and renal function, prostate and bowel tumour markers) and the swab of the pharyngeal cavity were normal.

Patient 3. A 65-year-old woman had developed her first episode of erythema, swelling and scarlatiniform peeling of the right thumb (fig. 3) in January 2006, without prodromal phase. No trigger factor was identified except a dental operation 6 weeks before.

Table 1. Patient data

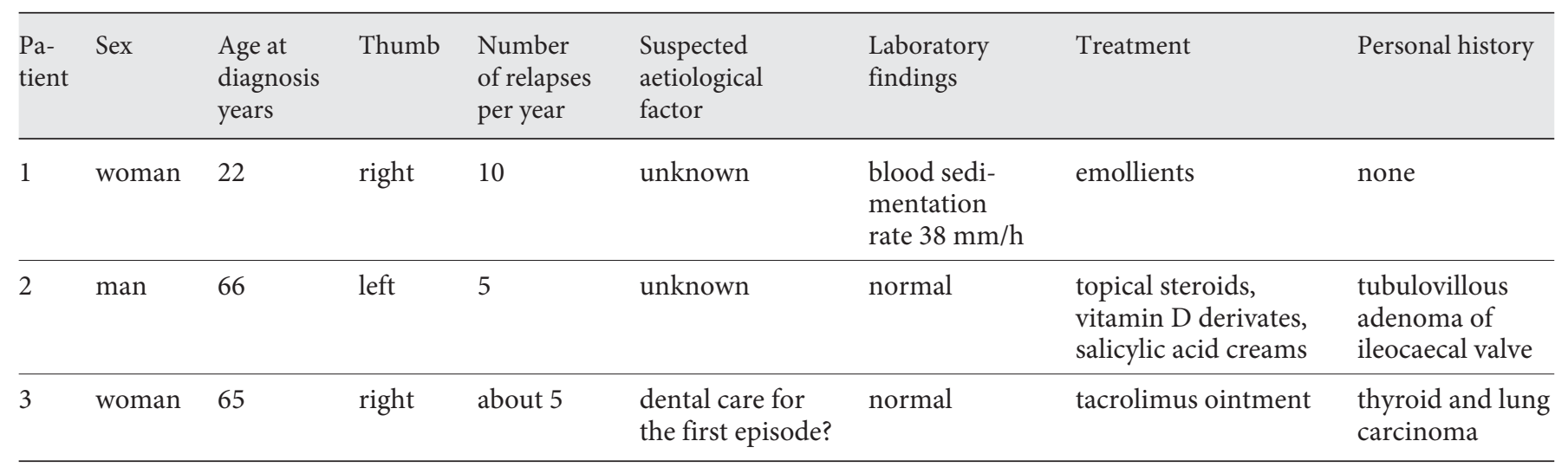

\section{KARGER}

(C) 2011 S. Karger AG, Basel

Fax +41613061234

E-Mail karger@karger.ch

www.karger.com 

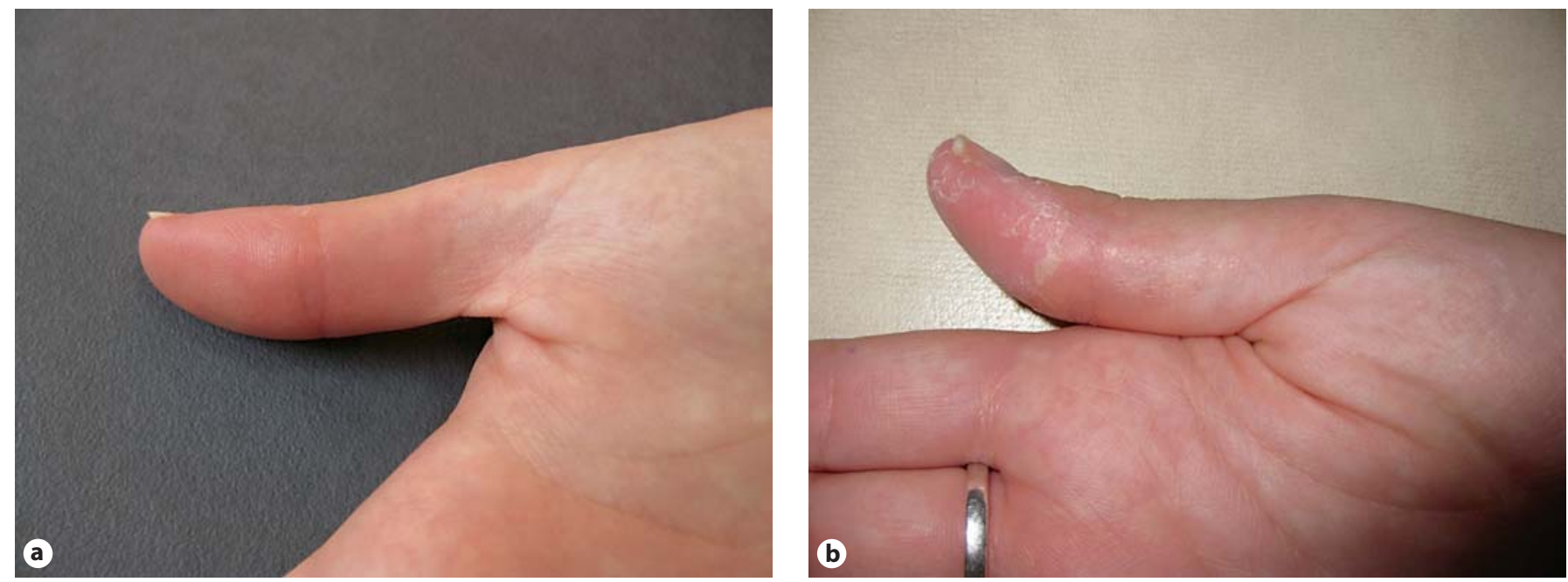

Fig. 1. a Beginning of the skin eruption with diffuse erythema of the right thumb, more pronounced on the distal phalanx. b One week later, large lamellar peeling of the finger. c Two weeks later, all previous clinical features spontaneously regressed, and we observe a slight postinflammatory erythema.
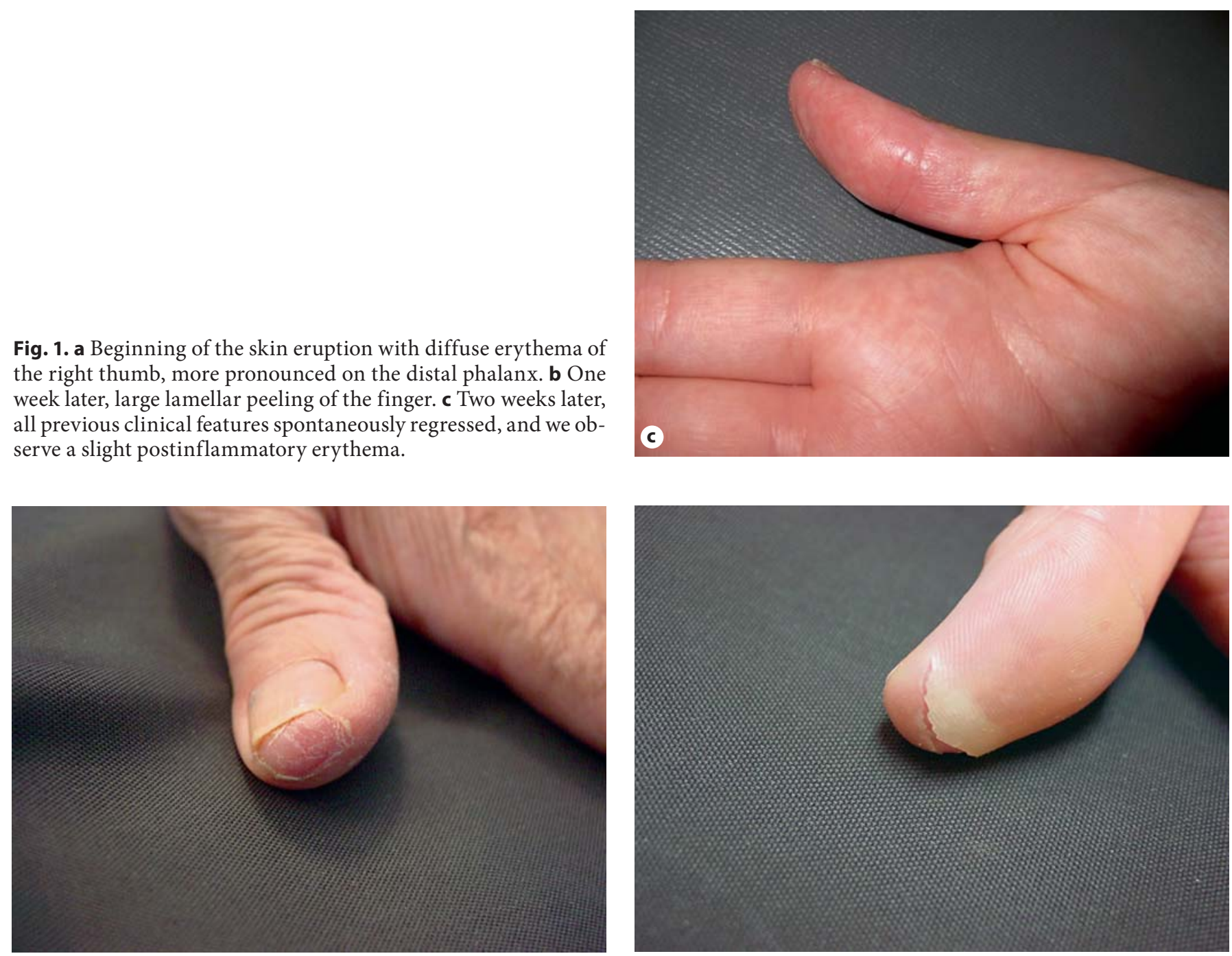

Fig. 2. One week after the beginning of the symptoms, erythema with lamellar peeling of the distal side of the left thumb of patient 2 .

Fig. 3. One week after the beginning of the erythema, characteristic lamellar peeling of the thumb. 
In 1997 she was operated for a papillary thyroid carcinoma, with adjuvant radiotherapy and substitution with thyroxine for a secondary hypothyroidism. All the laboratory examination performed during the clinical manifestations, as well as chest X-ray, antistreptolysin titre and bacterial culture of the pharynx were normal. A topical treatment with tacrolimus ointment $0.1 \%$ was not effective, and the clinical evolution was positive after about 2 weeks. After this first episode, relapsing was regularly observed, even after a new operation for a lung carcinoma in October 2007.

\section{Discussion}

ESDR was described for the first time by Féréol in 1876 [5], and about 60 cases are described in the literature, mainly the French and the German one. The clinical features are normally preceded by a prodromal phase, especially for the generalized forms; patients can complain of general malaise, headache, muscle and joint pain, nausea and gastro-intestinal disorders. Skin lesions are characterized by a macular confluent erythema, more or less localized, followed by a typical, gross lamellar, scarlatiniform desquamation, which occurs within 1 week after the beginning of the skin eruption $[1,2,4]$. In the face, the desquamation is more pityriasiform. At the histological examination, this desquamation occurs above the stratum granulosum. We do not observe any papules or pustules, blisters or hyperkeratosis. Other associated symptoms could include conjunctivitis, pharyngitis, white-gray tongue, epistaxis, hair loss, infections (pneumonia, enteritis), lymph node swelling and glomerulonephritis [2]. The first episode lasts about 2-4 weeks; it is self-remitting, and relapses are observed in a variable time, more often shorter and milder than the first. No specific treatment is helpful to shorten the evolution of this disease, in particular topical or systemic corticosteroids. Antibiotics could be helpful and prescribed if a concomitant bacterial infection is found, especially in the pharyngeal cavity. The diagnosis is clinical because histological examination and laboratory findings are not specific $[3,4]$ : we can observe an inflammatory syndrome (elevation of $\mathrm{C}$-reactive protein and blood sedimentation rate), with eosinophilia and a transient proteinuria and microhaematuria. The antistreptolysin titre is sometimes elevated, and a positive culture for Streptococcus can be found in the pharyngeal swab. In fact, the pathogenesis of this disease is not completely elucidated, but in the literature the supposed trigger factors are external, such as viral or bacterial infection (more frequently Staphylococcus aureus or Streptococcus) or drugs (hyperergic reaction) [4]. For the bacterial hypothesis, it is important to remember that one of the most important differential diagnoses are true staphylococcal (staphylococcal scalded skin syndrome) or streptococcal (scarlet fever, recalcitrant erythematous desquamating syndrome) infections - these bacteria could produce toxins responsible for the gross lamellar desquamation of the skin. Other diagnoses important to rule out are psoriasis, pityriasis ru- bra pilaris, Kawasaki syndrome, pellagra, peeling skin syndrome, necrolytic acral erythema, other palmoplantar keratoses or, finally, desquamatio aestivalis benigna. Fixed drug eruption could also be evoked in localized recurring inflammatory skin changes, but the colour of the lesion, more reddish than brownish, the irregular shape and the kind of desquamation were not typical of this diagnosis in our patients.

Our series is to our knowledge the first that describes an ESDR limited to thumbs. Localized forms previously described in the literature involve diffusely hands and/or feet [3]. In our patients, clinical features were highly characteristic of this disease and no evident trigger factors could be identified. No prodromal phase was reported by our patients except a slight general malaise in the 66-year-old male. Moreover, our patients did not present concomitant diseases. Furthermore, the histories of tubulovillous adenoma of the ileocaecal valve for patient 2 and of thyroid and lung carcinoma for patient 3 are probably not related to skin eruption because relapses were observed before the diagnosis of the tumour as well as after its treatment. In fact, a correlation with infections, inflammatory diseases (ulcerative colitis), atopy and medications has been described in the literature during ESDR $[4,6]$. The interest of this publication is to remember that morbus Féréol could involve just 1 finger (or more), with the typical clinical features reported in the literature. It is therefore important to think of this rare, but well-described, diagnosis - a 'forgotten disease' - as reported by Beltraminelli and Itin [4], when a patient complains of recurring erythema, swelling and gross lamellar desquamation of a finger.

\section{References}

1 Landthalter M, Michalopuolos M, Schwab U, Dorn M: Erythema scarlatiniforme desquamativum recidivans localisatum. Hautarzt 1985;36: 581-585.

2 Rosellen E: Erythema scarlatiniforme desquamativum recidivans. Med Welt 1966;48:2648-2649.

3 Braun-Falco M, Kasche A, Worret WI: Recurring localized scarlatiniform erythema Féréol-Besnier. Dermatology 2006;212:253-257.

4 Beltraminelli $\mathrm{H}$, Itin P: Erythema scarlatiniforme desquamativum recidivans - a forgotten disease (recurring localized scarlatiniform scaled erythema). Dermatology 2006;212:211-213.

5 Féréol N: Pseudo-exanthème scarlatiniforme récédivant. Bull Soc Méd Hôp Paris 1876;2/12:30.

6 Thiers H, Fayolle J, Coeur P, Laurent J: Erythème scarlatiniforme fixe avec rushs congestifs symptomatique d'une hémopathie lymphoréticulaire chronique. Bull Dermatol Syphil 1969;76:879-880.

Gionata Marazza, MD

Servizio di Dermatologia

Ospedale Regionale Bellinzona e Valli

CH-6500 Bellinzona (Switzerland)

Tel. +41 91811 8682, E-Mail gionata.marazza@eoc.ch 